ten convicted drivers repeat the offence within ten years-and an even larger proportion must have done so without being detected. The BMA recommended that a screening procedure for people at high risk should come into effect at $150 \mathrm{mg} / 100$ $\mathrm{ml}$, but the committee was influenced by "practical considerations": even at $200 \mathrm{mg} 100 \mathrm{ml}$ some 15000 drivers (including second offenders) would be included each year in the procedure, which requires drivers to provide evidence that they are no longer an undue risk before their licence is restored. Medical evidence will have an important part to play in this plan, so that it is unfortunate that so few doctors are available who are experienced in dealing with alcohol problems. It is as well to bear in mind that at $200 \mathrm{mg} 100 \mathrm{ml}$ we are talking about drivers who have taken 11-15 pints of ordinary beer or the equivalent in distilled spirits (11-15 "doubles") before driving. The committee's observation that this level "is hardly ever reached in normal social drinking" is therefore a gross understatement.

Of course, instruction in the safe use of the road system and the use of alcohol by young drivers should be regarded (as it is in other countries) as one of the most important functions of health education. The record of our road safety experts in this respect has been deplorable. The concentrated publicity campaign which accompanied the 1967 Act was never followed up, so that the very high risk group of young drivers (who represent the most serious problem today) have never been exposed to it and are mainly ignorant about the dangers of drinking and driving. Tragically, Graham Hill (a member of the committee) was killed in a plane accident before the report was published. We are told that he fully shared the committee's concern at the increasing toll of casualties caused by drinking and its desire to see urgent measures taken to reverse the trend. As a former world champion racing driver he would have done much to get the message across to the young.

This is a good report, and the committee's recommendations, which were unanimous and supported by the vast majority of those who submitted eviderice, could lead to a substantial reduction in mortality and morbidity. The report urges that the proposals be regarded as a package and not introduced piecemeal, so as to have the maximum impact. The main obstacle to this will be the vested interests of government departments. Perhaps we could learn a lesson from the French, who were so appalled by their road accident casualties that $M$ Girondeau, a young civil servant, was appointed to deal with the problem with direct responsibility to the Prime Minister overriding all government departments. The results were dramatic and have been lasting.

1 Road Safety Act 1967.

2 Report of the Departmental Committee on Drinking and Driving (Mr F Blennerhassett, chairman). London, HMSO, 1976.

${ }^{3}$ Baker, S P, in Preventive Medicine and Public Health, 10th edn. New York, Appleton Century Crofts, 1973.

${ }^{4}$ Ross, H L, fournal of Legal Studies, 1973, $2,1$.

\section{Transposition of the great arteries}

In transposition of the great arteries the aorta arises from the right ventricle and the pulmonary artery from the left ventricle. This condition occurs once in approximately every 4500 live births $^{1}$; so that each year in Britain between 100 and 200 affected infants are born. In spite of its rarity it is the most common life-threatening cardiac disorder encountered in the first month of life. Without treatment half the infants with transposition die in the first month, and less than $10 \%$ will survive to the age of 1 year. ${ }^{12}$

The basic problem in transposition is that the pulmonary and systemic circulations are separate and life is maintained only by communications which allow mixing of blood from the two circuits. The usual approach to treatment has been to perform a palliative operation to improve this mixing by creating an atrial septal defect. This was originally performed surgically, ${ }^{3}$ but more recently a balloon catheter has been used to enlarge the foramen ovale. ${ }^{4}$ The operation is done as soon as the diagnosis is established-in fact with the balloon technique it is generally performed at the diagnostic cardiac catheterisation. With balloon septostomy $70 \%$ of patients will survive the first year of life, but in most centres corrective surgery is performed electively between 6 months and 1 year of age. Up to the present the Mustard operation ${ }^{5}$ has been the corrective operation of choice in most patients. The interatrial septum is refashioned so that systemic venous blood is directed to the lungs via the left ventricle and pulmonary artery and the oxygenated pulmonary venous blood is directed to the body via the right ventricle and aorta. This operation can be performed with a low mortality, ${ }^{6}$ and in the intermediate term the majority of children lead full normal lives. Since, however, the basic anatomical lesion is not dealt with, the Mustard operation is not corrective in the strict sense of the word. Complications such as tricuspid incompetence have been encountered in a minority of patients and raise doubts about the ability of the right ventricle to serve as the systemic arterial ventricle for a normal life span.

Surgeons have therefore recently re-explored the direct approach to the correction of transposition by transferring the aorta to the left ventricle and the pulmonary artery to the right ventricle. Operations of this type were attempted without success $^{7-9}$ in the 1950 s and 1960 s. These early failures were in part due to deficiencies in cardiopulmonary bypass techniques and inadequate postoperative care, but with the general development of infant cardiac surgery these inadequacies have been overcome. One major problem remained unsolved: the technical difficulty of transferring the coronary arteries with the aorta. The two articles in this issue at pages 1109 and 1112 show that this technical difficulty has now been overcome.

This evidence that an arterial relocation operation can be successful raises the question of the place of such operations in the treatment of transposition. Relocation has limitations: such operations can be performed only in patients whose left ventricle sustains pressures similar to those encountered in the systemic arterial system but who have not developed severe pulmonary vascular disease.

Soon after birth regression of the fetal pulmonary vasculature leads to a fall in pulmonary vascular resistance, and unless a large ventricular septal defect or persistent ductus arteriosus is present, or there is pulmonary stenosis, in cases of transposition this change will result in a fall in left ventricular pressure and a diminution in left ventricular mass. ${ }^{1011}$ After the first week or two of life, therefore, half the infants with transposition will have left ventricles incapable of sustaining systemic arterial pressures. In such cases relocation operations would have to be performed in the early neonatal period. Even when the technical problems of arterial relocation in very young infants have been overcome, however, a substantial number of patients will not be referred to specialised centres until after their left ventricular mass has declined. These two reports of arterial relocation operations herald a new era in the 
surgery of transposition, but the present approach of primary balloon atrial septostomy followed by the Mustard operation will continue to be the mainstay of treatment for some time.

${ }^{1}$ Liebman, J, Cullum, L, and Belloc, N B, Circulation, 1969, 40, 237.

${ }^{2}$ Hoffheinz, H J, Glaser, E, and Rodewald, G, Zentralblatt für Chirurgie, $1964,89,326$.

${ }^{3}$ Blalock, A, and Hanlon, C R, Surgery, Gynecology and Obstetrics, 1950, 90, 1 .

${ }^{4}$ Rashkind, W J, and Miller, W W, fournal of the American Medical Association, 1966, 196, 991.

${ }^{5}$ Mustard, W T, Surgery, 1964, 55, 469.

${ }^{6}$ Breckenridge, I M, et al, Lancet, 1972, 1, 1140.

Bailey, C P, et al, Fournal of Thoracic Surgery, 1954, 27, 73.

${ }^{8}$ Kay, E B, and Cross, F S, Surgery, 1955, 38, 712.

${ }^{9}$ Idriss, F S, et al, Circulation, 1961, 24, 5.

10 Tynan, M, Circulation, 1972, 46, 809.

11 Lev, M, et al, American fournal of Cardiology, 1969, 23, 409.

\section{Politics and pharmaceuticals}

The drug industry has always ranked high among the capitalist ogres that enrage socialist politicians, and last year yet again the Labour Party's annual conference called for its wholesale nationalisation. A more moderate line has appeared in a discussion document ${ }^{1}$ published last week by a Labour Party working group chaired by Dr David Owen. This argues the case for the National Enterprise Board taking over "at least one" British company with a substantial interest in pharmaceuticals, so giving the State a foothold in the industry. The State company could, it is said, make better use of the legal provisions which allow licences to be granted to companies to manufacture drugs covered by patents-or at least the possibility would be there to discourage companies from making very high profits on a particular drug. The State company could undertake long-term research in areas of social importance but little commercial attraction; and it could provide the Government with data on the true costs of production and research within the industry. Other recommendations include a revision of the voluntary pricing system to bring it within statutory price controls and the use of planning agreements to encourage companies to pursue research developments of practical importance to the NHS.

Predictably, the discussion document also attacks the cost and content of much current pharmaceutical advertising and the quality of information about drugs supplied to doctors. It calls for a substantial cut in sales promotion (the subject of current private discussions between the industry and Dr Owen in his Government capacity), the abolition of free gifts and samples, and tighter controls on the content of pharmaceutical advertising. Prescribers' fournal should be expanded; doctors should be made more aware of the relative costs of similar drugs; and it discusses the possibility of ranking drugs into those of first choice for specific indications and those which are second or third line choices.

The tone of the document is reasoned enough, and the case it argues plausible-given its underlying premises that the pharmaceutical industry's profits are excessive and that State participation in profitable industries is a self-evident benefit to the British economy. Once again, however, we may ask what use has been made of experience in other countries. $\mathrm{Dr}$ Owen was quick to stress the success of the State-owned Renault car company in an international, competitive industry: there are no comparable success stories by State-owned pharmaceutical firms. With all its drawbacks-the extravagance of some promotion campaigns, the doubtful qualities of some drugs still widely advertised, the big profits by some companies, and the wasteful and excessive prescribing by some doctorsthe combination of a capitalist industry and a State health service has in fact given our.patients medical care of reasonable quality and safety. Has any other country devised a better system? Many have worse.

No one disputes that there is some truth in the criticisms made of the current practices of the drug industry in Britain, though the picture painted by Dr Owen's group is naturally darker than most. But the changes, controls, and restrictions proposed in the document are based on beliefs and not on facts. What evidence is there that State-directed research is of greater benefit to the community than that directed by commercial concerns? Already the universities and the research councils, with their enviable record of achievement and independence, are facing massive cuts in their budgets. Is there really any evidence that Government money would be better spent on acquiring a research-based drug firm? The same criticism may be made of the rest of the document. The ideas sound reasonable and are well intentioned; yet the NHS patient gets his drugs more cheaply than in almost any other technically advanced country this side of the iron curtain, and it makes little sense to upset an applecart that looks in betterthan-average shape. Certainly it is part of the socialist tradition to be active and reformist: but the Labour Party's preoccupation with the pharmaceutical industry, like its obsession with private beds, betrays its poor assessment of the real priorities for the nation's health.

${ }^{1}$ Public Control of the Pharmaceutical Industry. London, the Labour Party, 1976.

\section{International studies of risk factors for coronary heart disease}

Mortality rates from coronary heart disease (CHD) vary enormously throughout the world; even among the developed countries the variation is remarkable. The highest rates in middle-aged men are found in Finland-for men aged 45-54 years the rate is over 400 per 100000 per year-and in the United States the rates are nearly as high. Scotland is well known to have higher rates than England and Wales, though no clear explanation can be given for this, and the rates in Britain as a whole are substantially higher than in several other European countries, including Sweden and Italy. The lowest mortality in an industrialised country is found in Japan; for middle-aged men the rate is less than $10 \%$ of that in Finland. Analysis of trends in death rates ${ }^{1}$ and assessment of reporting methods ${ }^{2}$ suggest that the international differences are not due simply to variations in diagnostic habits.

Community studies have identified the major factors associated with an increased risk of clinical CHD, and comparisons of the results obtained in different countries have indicated that the levels of these "risk factors" tend to be higher where death rates for $\mathrm{CHD}$ are higher. Nevertheless, such are the errors that can be introduced if different methods are used, for example, for estimating serum cholesterol, for classifying electrocardiograms, or even for defining CHD, that comparisons of results from uncoordinated studies may be quite misleading. The use of reference laboratories and standardised classifica- 